\title{
Remote Sensing for Crop Water Management: from Experiments to User-Driven Services
}

\author{
Alfonso Calera ${ }^{1,}$; Isidro Campos ${ }^{1,}$; Anna Osannn; Guido D'Urso'; ${ }^{2}$ Massimo Menenti ${ }^{3}$ \\ ${ }^{1}$ GIS and Remote Sensing Group. Instituto de Desarrollo Regional. Universidad de Castilla-La Mancha. \\ Campus Universitario SN. Albacete, Spain. \\ ${ }^{2}$ Department of Agricultural Sciences, University of Naples Federico II, Via Università 100 Portici (NA), Italy \\ ${ }^{3}$ Department of Geoscience and Remote Sensing. Delft University of Technology. Stevinweg 1, 2628 CN, \\ Delft, The Netherlands. \\ *Correspondence: alfonso.calera@uclm.es (A.C.); isidro.campos@uclm.es (I.C.)
}

\begin{abstract}
The experiences gathered during the past 30 years support the operational use of irrigation scheduling based on frequent multi-spectral image data. Currently, the operational use of dense time series of multispectral imagery at high spatial resolution makes monitoring of crop biophysical parameters feasible, capturing crop water use across the growing season, with suitable temporal and spatial resolutions. These achievements, and the availability of accurate forecasting of meteorological data, allow for precise predictions of crop water requirements with unprecedented spatial resolution. This information is greatly appreciated by the end users, i.e. professional farmers or decision-makers, and can be provided in an easy-to-use manner and in near-real-time by using the improvements achieved in web-GIS methodologies. This paper reviews the most operational and explored methods based on optical remote sensing for the assessment of crop water requirements, identifying strengths and weaknesses and proposing alternatives to advance towards full operational application of this methodology. In addition, we provide a general overview of the tools which facilitates co-creation and collaboration with stakeholders, paying special attention to these approaches based on web-GIS tools.
\end{abstract}

Keywords: Crop Water Requirements; Irrigation Requirements; crop coefficient; web-GIS; Earth Observation; evapotranspiration.

\section{Introduction}

Pressure on water use is globally increasing and water demand for agriculture is the main driver for this pressure in many countries. The current demand of fresh water for agriculture in the world is unsustainable as recognized by FAO [1]. However, in spite of these increasing pressures, irrigation intensification is required to increase for food production for a growing population [2]. One of the possible ways to solve this dilemma could be the improvement of the efficiency in water use for irrigation to achieve a sustainable intensification of irrigated agriculture, in line with the definition of Garnett et al. [3] as "to produce more outputs with a more efficient use of all inputs (including knowledge and know-how) on a durable basis".

In the scheme of crop management, a good first step towards the improvement of water use efficiency is the adequacy of the water applied to the actual crop requirements, pointing to the necessity of adequate estimates of the net irrigation water requirements (NIWR). NIWR is the water that must be supplied by irrigation to satisfy evapotranspiration, leaching, and miscellaneous water supply that is not provided by water stored in the soil and precipitation that enters the soil [4]. So, calculation of NIWR requires estimation of crop water requirements CWR and soil water balance where crop evapotranspiration (ETc) is the main component. A huge body of knowledge has been growing in recent decades to estimate ETc, CWR and NIWR. Manuals used worldwide to determine 
CWR and NIWR, like FAO24 [5] and FAO56 [6], are milestones tracking this path, closely related with those that describe the relationships between yield and water, like FAO33 [7] and FAO66 [8]. Nevertheless, the complex interactions between root zone soil moisture flow, salinity build up, drymatter production, water quality degradation and opportunities to recycle water according to prevailing geo-hydrology and drainage conditions will require the use of more complex models describing the system with sufficient detail [9].

Most extension and irrigation advisory services at local and national scales were built on the wave of the "Green Revolution" to help farmers supply the right amount of water to the crops to improve the efficiency in the water use for irrigation. Nevertheless, better matching temporal and spatial water supply to the actual crop demand is a challenging key issue for sustainable intensification, in addition to nutrient supply and other agrochemical inputs. Despite its relevance and the efforts already achieved, water management still faces a development bottleneck -it requires precise information about the soil and plant conditions consistent across farms and from year to year. In addition, this information must be available at the right temporal and spatial scales that match rapidly-evolving capabilities to vary cultural procedures, irrigation and agrochemical inputs [10].

Remote sensing imagery from cameras on board satellites, aerial platforms, airplanes, or similar systems has been recognized as an exceptional tool to produce spatial information about ETc. Nevertheless, the lack of availability of timely images at the required spatial resolution, to be able to capture the within-field variability of crop conditions over the growing cycle, has been hindering the use of remote sensing approaches in practical applications. In 1984, in a seminar essay on the potential use of remote sensing for making day-to-day farm management decisions, Ray Jackson [11] stressed the overall importance to the growers of (a) timeliness, (b) frequency and (c) spatial resolution of data. His observations have remained relevant; but the advances in communication technology and computing, together with a large change in NASA data policy by the US government, giving open and free access via the internet to the georeferenced Landsat images in near real-time, are removing these barriers. The adoption by the European Space Agency of the same data policy, giving free and open access via the internet to the 10-m imagery acquired by Sentinel- 2 is revolutionizing the satellitebased remote sensing system for spatial resolutions in the range 10-30 m. In addition, an increasing number of commercial sensors at very high spatial resolution 1-5 m, WorldView2, PLEIADES, DMC and DEIMOS, are ready to provide frequent land observations with increasing capabilities.

Currently the operational use of dense time series of remote sensing (RS)-based multispectral imagery at high spatial resolution is able to monitor the crop biophysical parameters related with crop evapotranspiration and crop water use across the growing season, with suitable temporal and spatial resolutions. One most prominent and direct application of these approaches in agriculture is irrigation management. As described by Allen et al. [12] the benefits of these methodologies with respect to most classical information sources (field measurements or general knowledge) are the possibility to cover large areas, enabling sampling at high spatial resolutions and the zonation and/or integration over diverse areas. In addition, these procedures are generally more economical than point measurements. The literature is abundant in RS-based ET models or model-variants and validations of these models in different environments, surfaces and managements. Every model has strong scientific bases and are well calibrated for ET assessment at particular temporal and spatial scales. The experiences carried out within the PLEIADES project have confirmed that RS is a mature technology ready to be transferred to operational applications in irrigation management [137] and the technological transfer has already begun, where farmers find economical incentives to increase the irrigation efficiency [13]. Nevertheless, the translation of ET estimates into irrigation requirements and recommendation needs further development and it involves additional engineering methods and operative issues. In addition, the physical meaning of the results is different for the various ET models and these results have different applications in agriculture. Both aspects must be considered 
prior to recommending the most adequate model for different purposes and, from our point of view, the scientific literature is scarce in reviews analyzing these aspects.

In this framework of research and practical application, this paper reviews the basis of the most common methods based on RS for ET assessment with the focus on irrigation assessment in agriculture. We provide a comprehensive review of the basis of these models and their applicability, identifying the strengths and weaknesses and proposing alternatives to advance towards full operational application. Considering that these approaches are eminently applied, this paper also contains guidelines needed to provide a realistic estimation of remote sensing based CWR and NIWR in operative schemes and an extensive description of the most operational decision support systems based on this methodologies.

\section{Remote Sensing-Based Estimates of Evapotranspiration}

Most of the methodologies for ET assessment based on RS data are based on the big leaf area model $[14,15]$ and further developments of the Penman-Monteith equation. This schematization relies on the surface energy balance and the resistances approach for describing transport of water vapor, distinguishing between bulk surface and aerodynamic resistances [15]. The Penman-Monteith equation can be applied to estimate evapotranspiration once surface and aerodynamic resistances are properly determined for a crop cover of given characteristics, namely hemispherical surface albedo, Leaf Area Index (LAI) and height, as well as meteorological conditions and soil water status. In the context of irrigation scheduling, the Penman-Monteith equation has been implemented in the standard procedure for estimating crop water requirements, commonly known as the FAO-56 method [6]. In this procedure, the concept of evapotranspiration under standard conditions is formalized, i.e. "from disease-free, well-fertilized crops, grown in large fields, under optimum soil water conditions and achieving full production under the given climatic conditions" [Part B, 5].This definition allows for considering a minimum value of the stomatal resistance driving the transpiration process, which essentially becomes a function of the crop development, through the above-mentioned characteristics. This approach, defined in [6] as the "direct calculation", needs crop characteristics measured or estimated for each crop patch. Diversely, for a water stressed crop, the surface resistance increases according to the physiological response mechanisms which are characteristics of each species. The evapotranspiration under non-standard conditions hence requires additional data to solve the surface energy balance or to compute the soil water balance.

The direct calculation has been used to improve the definition of reference ET, ETo, by considering a well-watered hypothetical grass surface having fixed crop height $(0.12 \mathrm{~m})$, albedo $(0.23)$ and LAI (2.88). Then the FAO-56 promotes the concept of crop coefficients in the so-called "two-step" procedure $[5,6,16]$, which is now widely used in irrigation practice. In this procedure, ET is estimated as a product of two factors [6]. The first factor is the evaporative power of the atmosphere, ETo. The second factor in the "two-step" approach is the crop coefficient, Kc, which includes three parameters: a transpiration coefficient or basal crop coefficient, $\mathrm{Kcb}$, the evaporative component of the bare soil fraction, Ke, [17] and the water stress coefficient, Ks, which is related to the soil water content through the water balance in the root soil layer. In this framework, the Kcb is defined as the ratio between plant transpiration in the absence of water stress and reference ETo. In contrast with the strong temporal variability of ET values, the evolution of Kcb over the time can be represented by a smooth continuous function. Depending on the variable measured from satellites, three main RS approaches for ET estimation have been applied: a) based on surface energy balance (RSEB), b) reflectance-based crop coefficient (reflectance-based $\mathrm{Kcb}$ ) and c) by directly applying remote sensing-based parameters into the Penman-Monteith equation (RS-PM). The Figure 1 shows a schematic representation of the framework for the integration of the different models for the assessment of CWR and NIWR. 


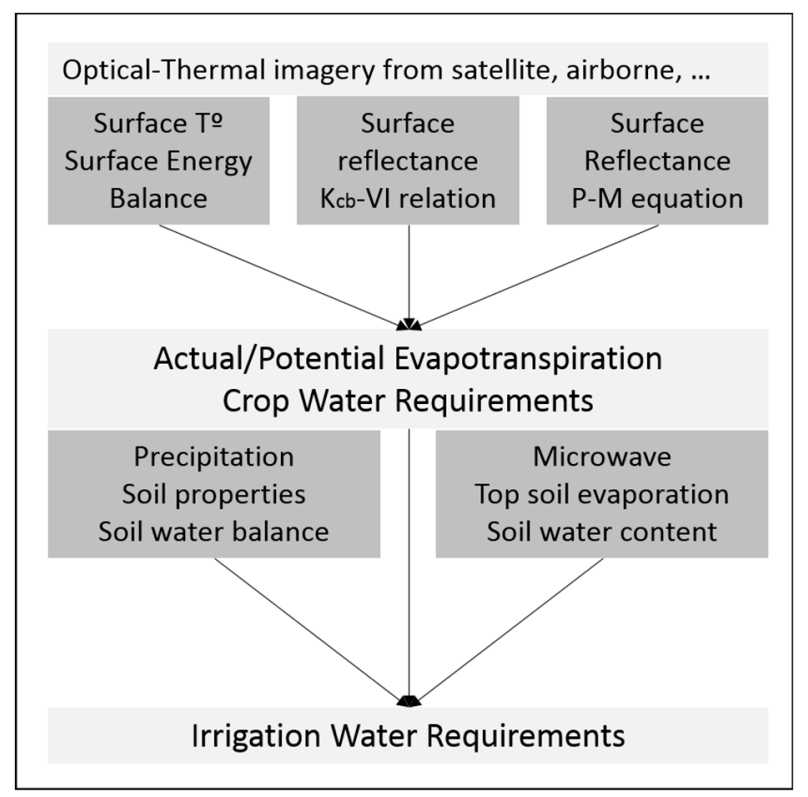

Figure 1. Overview of the remote sensing-based approaches for estimates of ET and Net Irrigation Water Requirements. The spatial scale of these approaches is related with the pixel size of utilized image data.

\subsection{The Reflectance-Based Basal Crop Coefficient (Kcb)}

The initial research relating crop development and canopy reflectance was developed during the 1970s [18,19] and much of this work had its foundation in research developed during the 1960s, as compiled by Pinter et al. [20]. Some of these authors already postulated the possible use of these relationships for the estimation of crop transpiration and the desirable use of these approaches for irrigation assessment in operative scenarios [21]. Following the development of the "two-step" procedure, some pioneers provided empirical evidence about the direct relationship between the Kcb values with the VI derived from multispectral satellite images [22-24] (see Figure 2).

Despite the empirical evidence, the physics underlying the Kcb-VI relationships was controversial. The arguments in favor of the causal Kcb-VI relationship include the direct relationship between $\mathrm{Kcb}$ and the fraction of photosynthetic active radiation absorbed by the canopy (fPAR) and the relationship of these parameters with the VIs. Some analytical approaches relating Kcb-VI and fPAR were proposed by several authors during the following decades [25-30].

The initial relationships already presented were developed in terms of empirical values of VI and tabulated or common values for herbaceous crops, such as wheat and corn. The development and popularization of different methods for the measurement of crop ET, such as lysimeters, eddy covariance and Bowen ratio techniques, provided a new source of data for the development of empirical Kcb-VI relationships and a large number of crops were added to the classical species. Some examples are the Kcb-VI relationships derived and evaluated for potato [31], cotton [32], sugar beets [33] and vegetable crops including garlic, bell pepper, broccoli, and lettuce [34]. The advantage of using Kcb-VI is recognized for almost every crop, but the benefit of these methods applied to fruit trees is of paramount importance. The differences in local practices (planting densities, plant architecture and the management of the crop understory) have a great effect on the actual value of the crop coefficient and studies have demonstrated the capability of the Kcb derived from VI to capture these variations. Along this line, successful developments have been made for pecan trees [35], vineyards [36,37], and apples [38], and several attempts have been made in natural vegetation $[39,40]$.

In addition to the previous research, based on ground based measurements of ET, special attention should be paid to those relationships based on VI data and ET estimated based on thermalbased remote sensing models [41-43]. These methods allow for a determination of latent heat fluxes, hence the actual ET of crops. When these methods are applied over irrigated areas (where in most 
cases evapotranspiration can be considered under standard conditions) they result in a massive calibration of the single Kc-VIs relationships without the necessity of cumbersome and expensive field campaigns measuring ET.
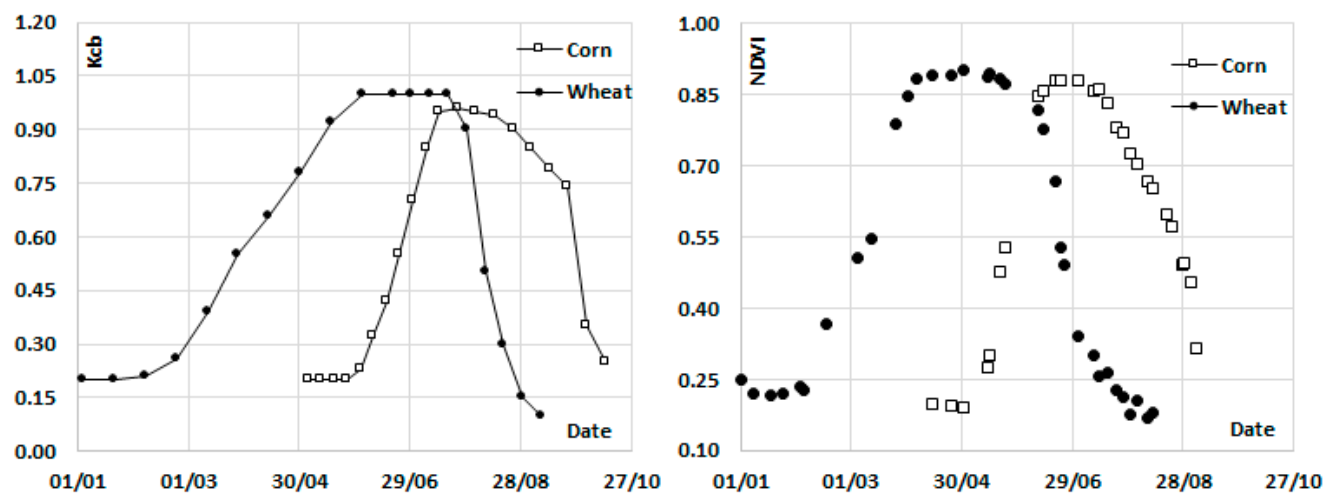

Figure 2. Comparison of the Kcb curves described by J.L. Wright in 1983 [17] for wheat and corn and the temporal evolution of NDVI for both crops in Albacete (Spain) during the 2016 growing season.

\subsection{Remote sensing based Penman-Monteith direct approach-es (RS-PM)}

As mentioned before, the direct calculation of the Penman-Monteith equation can be used to estimate the maximum fluxes of evaporation from soil $(E)$ and transpiration from plant leaves $(T)$ once provided with the canopy parameters related with the surface properties [62]; essentially the surface and canopy resistances ( $r_{s}$ and $r_{c}$ respectively) and the net radiation $(R n)$. These parameters are, in turn, related to three parameters derived from RS data: namely, the leaf area index (LAI), the crop height $\left(h_{c}\right)$, and the surface albedo $(r)$. The variable $r_{c}$ is inversely related to the active LAI and, in turn, dependent on the maximum resistance of a single leaf. The active LAI is the index of the leaf area that actively contributes to the surface heat and vapor transfer [6]. It is generally the upper, sunlit portion of a dense canopy and can be approximated by $0.5 \times \mathrm{LAI}$ [62]. The maximum resistance of a single leaf is crop-specific and differs among crop varieties and crop management [6], but a fixed value of $100 \mathrm{~m} / \mathrm{s}$ can be considered in operative approaches [62]. The canopy architecture parameter used in the estimation of $r_{c}$ is the canopy height. Although the formulation can vary depending on meteorological conditions (stability) it is generally accepted that, in agricultural fields under wellwatered conditions, the stability correction is not needed. In addition, in most cases for irrigated environments the radiative component of the Penman-Monteith equation is dominant over the aerodynamic term; hence, a fixed value of crop height can be considered (i.e. $0.4 \mathrm{~m}$ for herbaceous crops, $1.2 \mathrm{~m}$ for tree crops) without significantly affecting the final accuracy. There is substantial literature on the estimation of the two most relevant canopy parameters, surface albedo and LAI from VIS-NIR observations, based either on empirical relationships with different VIs or physically-based methods, such as radiative transfer models [64,65]. This approach offers the advantage of a validation based on the estimated accuracy of albedo and LAI, the latter easily measurable in the field by means of portable optical analysers. A similar methodology is the base of the MOD16 global ET product $[66,67]$ and further applications in natural vegetation and regional scales [68-71]. This method has been evaluated for ET estimates and irrigation management at the scale of irrigation schemes [72], in fruit threes $[63,73,74]$ and is the basis of an irrigation advisory service operational in Italy, Austria, and Australia [75].

\subsection{The Remote Sensing Surface Energy Balance}

The remote sensing surface energy balance approaches (RSEB) derive surface fluxes from the energy balance equation [79-82] by calculating the required variables from RS primary and secondary observables [83]. In particular, latent heat flux, $\lambda \mathrm{ET}$, is estimated as the residual term of surface energy balance equation: 


$$
\lambda E T=R n-G-H
$$

where $\lambda$ indicates the latent heat of the vaporization of water $\left(\mathrm{J} \mathrm{kg}^{-1}\right), \mathrm{Rn}$ is the net radiation flux (W $\left.\mathrm{m}^{-2}\right), \mathrm{G}$ is the soil heat flux and $\mathrm{H}$ is the sensible heat flux. The main observables are the bihemispherical surface reflectance, which determines $\mathrm{Rn}$, and the radiometric surface temperature $\left(T_{R}\right)$, derived from thermal band imagery, and used to compute the sensible heat flux. The different schemes of RSEB models differ as to how the difference between $T_{R}$ and the aerodynamic temperature, $T_{0}$, is addressed. This difference is needed to compute the sensible heat. $T_{R}$ and $T_{o}$ are clearly related [84], but this relationship is highly complex, since $T_{R}$ depends on the temperature of the different elements that occupy the radiometer view, while $T_{0}$ depends on surface aerodynamic roughness, wind speed, and the coupling of soil and canopy elements to the atmosphere.

The simplest RS-based SEB approaches use empirical/semi-empirical methods for adjusting $T_{R}$ to $T_{0}$, tuned to account for the spatial variability in the roughness lengths for heat and momentum transport [85-88]. Other approaches avoid the problem by computing the aerodynamic to air gradient, $\mathrm{T}_{\mathrm{A}}-\mathrm{T}_{\mathrm{O}}$, needed to compute the latent heat flux. These methods are based on selecting pixels in the satellite image representing the extreme heat and water exchanging surfaces. Then they calculate the spatially-distributed sensible heat flux, assuming a linear relationship between $T_{R}$ and the near-surface air temperature gradient across the image [79,89-91]. Other $T_{R}$-based approaches model the effects of partial vegetation cover on To using two-source model parameterizations [84,92], which partition surface fluxes between the soil and canopy components of the scene. This more physically-based approach does not require in situ calibration, although most implementations do require accurate radiometric temperature measurements. Anderson et al. [93] proposed an improvement of a two-source scheme by incorporating a simple description of planetary boundary layer dynamics. The resulting Atmosphere-Land Exchange Inverse (ALEXI) and an associated flux disaggregation technique (DisALEXI) is a multi-sensor thermal approach to ET mapping that reduces the need for ancillary data input and is able to deal with errors in $T_{R}$ remote estimation by using the rate of change in $T_{R}$ observations [94,95]. The partitioning of available energy through $T_{R}$ inherently accounts for the increase of plant temperature under water stress conditions $[21,96]$ and successful model validation under water stress conditions has been regularly published [82,97,98]. A comparison between a two-source model and an internally calibrated model over herbaceous crops [99] showed a reasonable agreement with ground measurements. This approach is very attractive in calibration and validation of the other approaches presented here [100] and for applications such as water stress assessment.

Water stress is an important indicator for the evaluation of adequate crop water management in precision agriculture. Stress indicators are useful to diagnose the causes of crop yield variability and develop management strategies [101] in water-limited environments. The most classical indicator of crop water stress that uses RS data without using direct measurements [83] is the crop water stress index (CWSI) based on the difference between air and canopy temperature [21,96]. Later development of the CWI considered the effect of partial canopy covers in the surface temperature, as is the case of the surface-air temperature and VI relationships [82], and further developments and simplifications $[80,102]$. The literature is profuse in the use of CWSI or similar indicators for the assessment of crop water status and irrigation scheduling [103-106]. These indices and other diagnostic tools, are indicators of the plant water status, revealing the effects of the water deficit, but they cannot predict the irrigation timing or amount needed to maintain the crop under optimum conditions. Other approaches to water stress, such as the hyperspectral indices, have gathered promising results in agriculture [107-110] in addition to other stress indicators based on multispectral satellite signal, such as the normalized difference water index (NDWI) [111], and are attractive for extensive applications in natural vegetation.

\subsubsection{Coupling Models}

The RS-SWB models provide continuous and predictive estimation of the soil water content, cumulative ET [113] and irrigation requirements. However, for an adequate estimation of these components the SWB model requires knowledge of the water inputs, precipitation, and irrigation, 
and the soil hydraulic properties, i.e. actual and maximum amount of soil water storage in the root zone, if classical static volume balance approaches are used. Accurate values of maximum and actual water content are necessary in every SWB model, although both concepts could be represented with different notations $[6,16,93,114]$. The actual content can be estimated when the balance is maintained for long periods, departing from dates when the soil can be considered at full capacity, but the uncertainties about the spatial variability of the water inputs (mainly precipitation) and the inaccuracy in estimating other components result in significant bias at large spatial scales and for long periods. In addition, the practical operation of these models is also limited by the narrow knowledge about the soil properties, which define the water retention, field capacity, and wilting point, in addition to the actual root depths for most of the crops growing in heterogeneous areas.

Within the six approaches classified by Wang-Erlandsson et al. [115], for the estimation of root zone water storage capacity, RS-based studies are generally based on field observations and look up tables [116-119]. Nevertheless, some recent studies propose the optimization-calibration and inverse modelling approaches with diverse purposes. Some approaches assimilate into the soil water balance models either water stress estimates based on canopy temperature [120,121] or ET estimates based on SEB models $[93,113,116,122]$ in order to calibrate the fraction of water depleted derived from the water balance model. In slightly different approach, some authors propose the integration of actual ET values in order to calibrate the soil water balance model in terms of the root zone storage capacity $[115,123-125]$. The rationale of these approaches is that any empirical approach to the plant water stress, or alternative formulations as those based on the canopy temperature, must be equivalent to the soil water stress, a stress index based on the parametrization of the soil properties [122]. Both approaches to water stress result in similar values only if the SWB model is properly initialized and maintained. Therefore, those variables with large uncertainties as is the case of the fraction of water depleted or the root zone storage capacity can be calibrated.

However, the lack of information about the actual irrigation scheduling adopted by the farmers is the critical limitation when applying soil water balance models. Irrigation criteria adopted by farmers depend on several factors related to operation and management of irrigation conveyance and distribution systems and to farmers' perception about the best time and duration of irrigation applications. This issue might be addressed by using deterministic or stochastic approaches to parametrize farmers' behavior [126]. Still, remote sensing is very valuable in this context since the knowledge of the actual development of crops is one of the most important variables in the description of this process.

\section{Operational Use of Remote Sensing for Irrigation Water Management}

\subsection{Monitoring the Crop Development at the Right Spatial and Temporal Scale}

Monitoring crop development and crop ET over the growing season for the purpose of irrigation management requires dense time series of multispectral imagery at spatial resolution high enough to resolve within-field variability and delivered in real-time. The spatial and temporal resolution of the resulting maps of ET and NIWR depend on the pixel size of the input imagery. In addition, and given that crop evolves rapidly in most cases, single satellite sensors or platforms cannot adequately capture these changes due to their limited temporal resolution and the impact of cloudiness in the optical and thermal satellite images. Virtual constellations of planned and existing satellites help to overcome this limitation by combining all available observations to mitigate limitations of any one particular sensor [127]. For models based on reflectance-based VI and further secondary variables, which rely on VIS-NIR imagery, the pixel size ranges usually between 5 and $30 \mathrm{~m}$ using most of commercial (World View, Rapid Eye, DMC, and Deimos) and free images from the sensors on L8 and Sentinel2a currently in orbit. Accordingly, the virtual constellation of L8 and Sentinel-2a currently provides, at no cost, a time resolution of around one image per week, which can be considered as a minimum for the adequate monitoring of crop development. The time series of both sensors are 
accessible through USGS (http://glovis.usgs.gov/) and Copernicus (https://cophub.copernicus.eu/) sites. In addition, some companies, like Amazon S3 (https://aws.amazon.com/es/public-datasets/landsat/) and Google Earth Engine (https://earthengine.google.com/), are offering catalogs of satellite imagery from both sensors at the planetary scale, and additional cloud computing capabilities. The use of multi-sensor virtual constellations is the only way to ensure the frequent availability of cloud-free images. Yet, the actual number of images effectively usable in an area or period can be seriously impacted by the clouds, even considering multiple platforms. Some initiatives, like the upcoming launch of Sentinel-2b, foreseen for 2017 (https://earth.esa.int/web/guest/missions/esa-operational-eo-missions/sentinel-2), will increase the availability of pixel-cloud-free imagery. Currently, as presented in the next section, the demand for irrigation recommendations and the implementation of operational services appears in areas characterized mostly by low precipitation and high atmospheric demand, which are only minimally affected by clouds. However, the implementation of these methods in areas of significant cloudiness must also be considered.

ET products based on RSEB can have medium spatial resolution for the most operational satellites. The pixel size ranges from $100 \mathrm{~m}$ for thermal sensor on board L8 to $1000 \mathrm{~m}$ for MODISAQUA, MODIS-TERRA and Sentinel-3; additional data sources and downscaling algorithms and interpolation methods can be used to improve the temporal and spatial resolution. From the point of view of crop management, the strength of these models is the assessment of surface ET also under water stress conditions and further indicators of water stress and irrigation performance. Nevertheless, the spatial resolution provided by the most operational platforms is not appropriate for small agricultural fields [12] since the pixels may overlay broad mixtures of crops and densities so that surface temperature signals are mixed and the ET retrievals are difficult to interpret. Therefore, from an operative point of view for irrigation management the procedures based on satellite canopy temperatures seems to be complementary with that previously described, providing an independent quality control in the suitable areas. Efforts are ongoing to implement disaggregation techniques to increase effective spatial resolution from satellite thermal imagery, reaching spatial resolutions comparable to the most common multispectral images [128]. In addition, the spatial resolution can be improved up to $2-5 \mathrm{~m}$ from aerial images, and growing advances on the use of airborne thermal cameras shows very promising perspectives to produce temperature maps at very high spatial resolution [108,129].

\subsection{RS-Based Irrigation Scheduling: Implementation}

As presented and discussed in the previous sections, time series of current multispectral imagery that provides canopy reflectance can be directly converted, either through Kcb-VI relationships, or using more complex models, into maps of $\mathrm{Kcb}$, or related variables describing the potential crop water use. Gap filling techniques between images close in time allow the production of daily maps of the variables of interest, LAI, $\mathrm{h}_{\mathrm{c}}$ or, directly, $\mathrm{Kcb}$, taking advantage of smooth-continuous curves described by these parameters and so avoiding the pernicious effects of cloudiness. The product of these Kcb maps and reference evapotranspiration, or the solution of the PM equation using RS inputs, directly provide the daily potential transpiration on a pixel by pixel basis. In addition, the interest of these methods goes beyond the perspective of irrigation management. Although it is not discussed in this paper, the output of this remote sensing-based soil water balance paves the way for water accounting at the pixel scale for water governance and environmental purposes, and promising perspectives are open to use this methodology together with ground flowmeters to enforce legal rules about monitoring permitted abstraction volumes to use for irrigation [130].

For the adequate determination of NIWR, both VI-based Kcb RS-PM models require the assessment of soil water content. For these reason, some of these approaches have been integrated into a classical soil water balance, like that described in FAO56 [6], demonstrating good performance 
for the assessment of irrigation water requirements $[117,131]$. The literature is prolific in soil water balance models, with different degree of realism and complexity, but the approaches based on remote sensing data are generally based on relatively simple models [116] because these approaches have a clear inclination for the operational applications at large scales. For these scales the detailed information about the soil properties is scarce [93]. According to the FAO56 procedures it is possible to calculate these RS-based NIWR irrigation water requirements also under water stress, as is used either in controlled deficit irrigation or in supplemental irrigation. Knowledge of the desired water stress degree is required and further calibration of the methodology and the evaluation of irrigation management using diagnostic tools is always recommended.

In these models soil evaporation is calculated by separately applying a soil water balance in the soil top layer as proposed by Allen et al. [6] and further modifications [49]. This approach requires the knowledge of the irrigation timing and amount, which is generally known in irrigation assessment scenarios. Alternatively, some authors working at large scales, with scarce field data, proposed the concept of synthetic crop coefficient [47] accounting for mean soil evaporation derived from canopy cover estimates. Microwave remote sensing could provide insight on the bare soil evaporation, although the scales of observation for the current sensors SMAP and SMOS $(20 \mathrm{~km})$ $[132,133]$ is too coarse for the agriculture scale of interest.

Some initiatives implementing satellite-based Irrigation Advisory services have been developed in Southern Italy, with IRRISAT (http://www.irrisat.it), in Lower Austria, with EO4Water (http://eo4water.com), and in Southern Australia, with IRRiEYE (http://www.irrieye.com). These systems are based on the RS-PM method [75]. Thus, the calculation of crop ET and suggested irrigation depth (pixel and plot scale) are based on the LAI calculation from surface reflectance values and meteorological data. EO data from the virtual constellation of Landsat 8, Sentinel-2, and DEIMOS are used to derive crop parameters (LAI and surface albedo) on a weekly basis. Information is released to end-users by using a webGIS tool, developed in an open-source software environment and implemented in three different areas. The structure of the webGIS has been slightly adapted to each area for considering the requirements of the local users. The IRRISAT approach has proven that economic benefits generated by such advisory services are able to fully repay the initial investments, creating advantages for the environment and opportunities for all of the users of water resources. Accordingly, IRRISAT has been deemed a "best practice" for agricultural applications by EURISY (http://www.eurisy.org/good-practice-campania-encouraging-the-sustainable-use-of-irrigationwater-in-the-region_85) and by the International Selection Committee of the call for "Best Sustainable Practices on Food Security" for EXPO 2015 in Milan (Italy). In the specific context of Consorzio of Sannio Alifano, Campania Region, the overall results in terms of cost-benefit analysis, obtained comparing the 2012 irrigation season (pre-IRRISAT) and 2013 (post-IRRISAT), demonstrate water savings of about $18 \%$, while a survey on a sample of monitored farms highlights peaks saving of about $25-30 \%$ without loss of production.

An approach using satellite data, mobile phones, and webGIS tools for information delivery is the IrriSatSMSsystem developed in Australia by CSIRO. The system is based on the NDVI-Kcb relationship [57] and was originally applied for vineyards in the Murrumbidgee Irrigation Area, but the current geographic area covers the entire Australian continent. The IrriSatSMS system aims to simplify input data collection requirements and reduce both costs and complexity of information output [134]. The core of the system was initially a server that acts as a data collection portal for various data feeds and a processing engine to convert these data into usable irrigation management information. The most recent version makes use of the Google Earth Engine for the image processing and algorithm implementation. Originally the system relied mainly on a Short Messaging Service (SMS) interface to communicate with irrigators directly on their mobile phones and later development included a web-interface (https://irrisat-cloud.appspot.com/). The web interface is easily accessible, the target fields can be defined (actually draw) by the user and the information contained in the system is well presented and easily reached. Some information about the crop type, management, growing cycle, and soil properties is required in order to complete the water balance.

In the framework of the NASA Terrestrial Observation and Prediction System (TOPS) [135], an application for near real-time mapping of crop canopy conditions and associated CWR at the 
resolution of individual fields has been developed. The TOPS Satellite Irrigation Management Support (TOPS-SIMS) integrates satellite observations from Landsat and MODIS with ETo from meteorological information and ancillary data on crop type and site-specific conditions. The initial implementation provides a capability for mapping fractional cover, associated basal crop coefficients, and evapotranspiration over 3.7 million ha of farmland in California's Central Valley. A generalized NDVI-Kcb relationship is used for near real time mapping Kcb and ETc. Refinements introducing crop-specific NDVI-Kcb relationships are introduced a posteriori when this knowledge is available [59]. A web-based user interface provides access to visualizations of TOPS-SIMS (http://ec2-54-19748-121.compute-1.amazonaws.com/dgw/sims/). The variable and date visualized can be selected and the data associated to the plot analyzed can be downloaded in numerical and graphical formats.

In Southern Spain, a first experience was developed in 2005, by using time series of Landsat5 images to obtain Kcb curves based on NDVI temporal evolution and displaying them on SPIDER (http://maps.spiderwebgis.org/webgis), a web-GIS based on open-source software developed by the University of Castilla-La Mancha. SPIDER has evolved from a 2005 prototype and it is currently providing time series of Sentinel-2a and Landsat- 8 imagery and derived products for the whole Iberian Peninsula, covering Spain and Portugal (around 600,000 $\mathrm{km}^{2}$ ). SPIDER is able to display time series of raster and vector maps, adding the capability to also display time trajectories of pixel-based values for the periods defined by the user. The main layers displayed by the systems are ETo maps, color composition RGB, NDVI, Kcb and CWR values, 24 hours after image delivery in the web-portals of L8 and S2a by USGS and Copernicus, respectively. The image processing is off-line and a normalization process allows the operation of multiple image sources as a multi-sensor virtual constellation. A mobile app version of SPIDER webGIS (Agrisat App) was released in 2016 and is available in the most common digital distribution platforms for mobile devices.

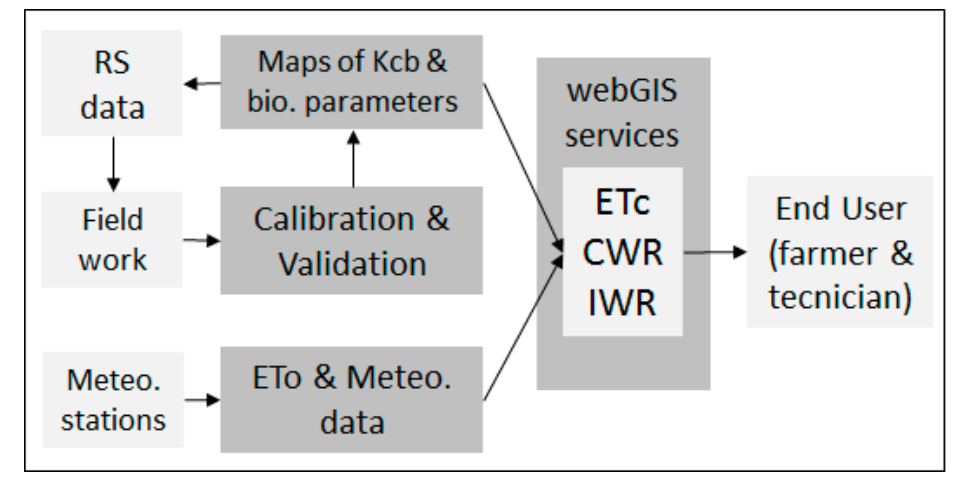

Figure 3. Scheme of the modular system based on the integration of Remote Sensing and weather observations into a webGIS, to provide users irrigation scheduling, matching the water supply to crop water demands.

\subsection{Predicting CWR a Week Ahead}

Providing advice in operative scenarios, one week ahead seems to be a reasonable anticipation, providing enough time and ensuring the accuracy of the CWR forecast. The relevance of this predictive product was already highlighted by [4] and clearly recognized by the traditional irrigation advisory services, but the remote sensing community was primarily interested on the accuracy of RSbased ET estimates. The prediction of CWR one week ahead requires the extrapolation of the Kc-Kcb data and weather forecasts for ETo prediction. CWR forecast is a logical step in the reflectance-based Kcb models [34,59], although some of the operational systems, like TOPS-SIMS still do not incorporate this product. A prediction of CWR is fully operative in IrriSatSMS and is under development for the IRRISAT, EO4Water and IRRiEYE systems based on LAI-VI relationships (De Michele, personal communication). A commercial development of the CWR prediction based on KcbVI relationships has been developed in Spain (http://www.agrisat.es). The initial approach is based on a generalized Kcb-VI relationship following previous approaches discussed in this paper [57,59]. 
Considering that ETo can be calculated from common meteorological data, ET can be calculated from short term numeric weather forecast. Two complementary methods with different spatial scope and accuracy have been introduced. The first one is to use the full power of numeric weather forecast to determine the variables required to compute ETo according the FAO56 formulation. The second one is based in daily temperature forecasting by using it as the input into Hargreaves and Samani equation to calculate ETo [6]. The latter method should be restricted to areas where the Hargreaves and Samani equation works well (no windy area, no coastal areas) and where no forecasting of other meteorological variables than temperature are available. An inter-comparison analysis has been recently published considering ensemble forecast models up to five days and a spatial resolution of $7 \mathrm{~km}$ [138]; this study, based on COSMO-LEPS data (provided by the European Consortium for localscale modelling, COSMO) has evidenced the robustness and reliability of ETo forecasts with the PM equation.

Computing ETo according FAO56 from weekly numeric weather forecast is the preferred option. Maps of weekly predicted ETo are routinely provided by the Spanish Meteorological Agency, AEMET (Agencia Estatal de Meteorología). The prediction is based on the High Resolution Limited Area Model (HIRLAM) and the European Center for Medium range Weather Forecasting (ECWMF) models. The spatial scope of this product is the Iberian Peninsula, as presented in Figure 4, and the spatial resolution of the raster map is a pixel size of $5 \mathrm{~km}$. The ETo predictions are routinely compared with the weekly measured ETo maps provided by the same agency and ETo values obtained from ground stations (www.siar.es). Finally, the adequate estimation of CWR requires the extrapolation of reflectance-based $\mathrm{Kcb}$, or related variables, like LAI and hc for RS-PM methods. This extrapolation takes advantage of the smooth shape of the Kcb curves derived from time trajectories of NDVI (see Figure 2). Therefore, the time trajectory of the $\mathrm{Kcb}$, and LAI or related parameters, are suitable to be extrapolated using previous dates for short periods, as is the case of one week.



Figure 4. Weekly reference evapotranspiration ETo forecasting provided by AEMET displayed by the system SPIDER webGIS. 


\section{Discussion}

\subsection{Strength and Weakness of the RS-based Models for Irrigation Assessment}

The great strength of the reflectance-based models from the point of view of crop irrigation management is the capability to estimate the potential crop transpiration, based on the temporal evolution of the RS-based Kcb and the ETo values. This ability of VI enables description of the photosynthetic magnitude of the canopy [44-46]. The theoretical and empirical bases support that reflectance-based basal crop coefficients represent the "potential" or maximum ratio between transpiration and ETo for the canopy, as it happens for an unstressed canopy following the definition of the Kcb concept. The advantages of VI-based Kcb estimation for irrigation assessment are clear as proposed by Allen et al. [12] in a review about the methods used for ET estimation: a) probably the simplest method to introduce the RS data in the operational application of the Penman-Monteith formulation for ET assessment known as the "two-step" methodology, which enables quick analyses that can be made by mid-level technicians; b) large areas can be covered; and c) very high spatial resolution if aerial imagery is used. As indicated by the same authors, the main weakness of the methods based on the Kcb-VIs for crop ET assessment are: a) the estimation of the evaporation component (from soil) is less certain than the transpiration component because of the lack of a direct relationship with vegetation amount; $b$ ) the relationships tend to overestimate transpiration under conditions of acute water shortage and c) the relationships may vary with the type of vegetation; stomatal control (and thus Kcb-VI relationships) can vary among types of vegetation.

The variation in the Kcb-VI relationships can be perceived in the compilation of equations based on the most used multispectral vegetation indices, NDVI and SAVI, presented in the Table 1. The relationships shown in Table 1 revealed a similarity for those relationships that reach the maximum NDVI or SAVI values, typically around 0.9 for NDVI and 0.7 for SAVI, resulting in a mean Kcb value of 1.14 and standard deviation (SD) equal to 0.08 . The main differences appear for bare soil, being the corresponding NDVI value around 0.15 and SAVI value around 0.1. Some relationships consider a minimum Kcb equal to 0 for bare soil $[29,30,33,47]$, arguing that no transpiration occurs for bare soil conditions. Other $\mathrm{Kcb}-\mathrm{VI}$ relationships are established in terms of a Kcb values greater than 0 for bare soil conditions $[22,34,36,48]$. This has been recurrently analyzed in the literature, as early as Wright [17] and Allen et al. [6]. Torres and Calera [49] demonstrated empirically that this residual Kcb can be expected for bare soil conditions and should be attributed to the evaporation component rather than plant transpiration [47]. The discussion about the most adequate minimum Kcb in reproducing the crop ETc is still open and further detailed analysis will be necessary for providing a practical solution.

Differences in the VIs measured with different instruments, and the difficulty to measure canopy transpiration, in addition to the effects of the crop physiology and structure in the ET process could be in the basis of the mentioned discrepancies. The effect of the measurement instruments depends on the sensor's spectral and radiometric resolutions [50], differences in the acquisition angle [51,52], atmospheric correction, sensor degradation, and the correctness of the calibration process [53]. These sources of uncertainty can be minimized by applying cross-calibration approaches and ensuring the compatibility of the data-sources [50]. Additional differences might be attributed to the welldocumented variances in the stomatal response for the different species $[54,55]$ in contrast to the insensibility to these changes of the VI used for the assessment of Kcb.

Some Kcb-VI relationships exhibit very good agreement for different crops. Odi-Lara et al. [38] and Campos et al. [56] found that the relationship described by Campos et al. [36] in row vineyards was adequate for ET assessment in apple trees and Mediterranean holm oak savanna. Hornbuckle [57] concluded that several relationships, developed for multiple different crops [58] are valid for the assessment of vineyard ET in Australia. Melton et al. [59] proposed the use of a generalized relationship for real time and operational purposes, and apply crop-specific relationships a posteriori, when information about crop architecture is available. 
Table 1. Compilation of Kcb-VI relationships found in the literature.

\begin{tabular}{|c|c|c|}
\hline Crop & Equation & Reference \\
\hline Corn & $\mathrm{Kcb}=1.36 \times \mathrm{NDVI}-0.06$ & {$[22]$} \\
\hline Wheat & $\mathrm{Kcb}=1.46 \times \mathrm{NDVI}-0.26$ & [29] \\
\hline Cotton & $\mathrm{Kcb}=1.49 \times \mathrm{NDVI}-0.12$ & [32] \\
\hline Wheat & $\mathrm{Kcb}=1.93 \times \mathrm{NDVI}^{\wedge} 3-2.57 \times \mathrm{NDVI}^{\wedge} 2+1.63 \times \mathrm{NDVI}-0.18$ & {$[60]$} \\
\hline Wheat & $\mathrm{Kcb}=1.64 \times \mathrm{NDVI}-0.12$ & {$[30]$} \\
\hline Row vineyard & $\mathrm{Kcb}=1.44 \times \mathrm{NDVI}-0.1$ & [36] \\
\hline Garlic & $\mathrm{Kcb}=-1.56 \times \mathrm{NDVI}^{\wedge} 2+2.66 \times \mathrm{NDVI}-0.08$ & [34] \\
\hline Bell pepper & $\mathrm{Kcb}=-0.12 \times \mathrm{NDVI}^{\wedge} 2+1.45 \times \mathrm{NDVI}-0.06$ & [34] \\
\hline Broccoli & $\mathrm{Kcb}=-1.48 \times \mathrm{NDVI}^{\wedge} 2+2.64 \times \mathrm{NDVI}-0.17$ & {$[34]$} \\
\hline Lettuce & $\mathrm{Kcb}=-0.11 \times \mathrm{NDVI}^{\wedge} 2+1.39 \times \mathrm{NDVI}+0.01$ & [34] \\
\hline Corn & $\mathrm{Kcb}=1.77 \times \mathrm{SAVI}+0.02$ & {$[61]$} \\
\hline Potato & $\mathrm{Kcb}=1.36 \times \mathrm{SAVI}+0.06$ & [31] \\
\hline Sugar beet & $\mathrm{Kcb}=1.74 \times \mathrm{SAVI}-0.16$ & [33] \\
\hline Row vineyard & $\mathrm{Kcb}=1.79 \times \mathrm{SAVI}-0.08$ & [36] \\
\hline Cotton & $\mathrm{Kcb}=1.74 \times \mathrm{SAVI}-0.16$ & [47] \\
\hline Garlic & $\mathrm{Kcb}=1.82 \times \mathrm{SAVI}-0.16$ & [47] \\
\hline Olive & $\mathrm{Kcb}=1.59 \times \mathrm{SAVI}-0.14$ & [47] \\
\hline Mandarin & $\mathrm{Kcb}=0.99 \times \mathrm{SAVI}-0.09$ & [47] \\
\hline Peach & $\mathrm{Kcb}=1.29 \times \mathrm{SAVI}-0.12$ & [47] \\
\hline Apple trees & $\mathrm{Kcb}=1.82 \pm 0.19 \times \mathrm{SAVI}-0.07 \pm 0.06$ & [38] \\
\hline
\end{tabular}

The RS-PM methods are also in surface reflectance, thus the strength and weakness are similar to the reflectance-based Kcb models. The RS-PM approach solves the problem of the estimation of the resistances in the Penman-Monteith formulation for the conditions of a well-watered canopy. The parameters used in the respective solutions are strongly related with RS data and the key parameters, LAI, albedo and $h_{c}$, and these variables describe smooth-continuous functions that can be easily interpolated over time. The weaknesses are in the crop-specific LAI-VIs and hc-VIs relationships, the impossibility to reflect the effect of the water stress in the ET process and the role of the soil evaporation. In a complete analysis of the LAI-VIs, Anderson et al. [76] concluded that the LAI-VIs relationships were relatively stable for two different crops (corn and soybean) using determinate VIs. Similarly, Vuolo et al. [77] concluded that the models and calibration parameters used to estimate LAI from VIs can be transferred across different environments, management practices, and for multiple crops, including alfalfa, corn, sugar beet, and vineyards. In addition, according to the sensitivity analysis published by Consoli et al. [63] and D'Urso [62], the deviation of ET values by considering a constant value of $h_{c}$, over a wide range of leaf area indices, is lower than $10 \%$. Furthermore, the availability of sensors with improved spectral and spatial resolution such as MSI on board the Sentinel-2 satellite allows the application of inversion methods to canopy radiation transfer models to estimate crop biophysical parameters with greater reliability compared to other methods. These methods take into account the bidirectional reflectance distribution effects of the canopy as well as the actual illumination-viewing geometry of the sensors. Artificial Neural Networks have proven to be effective in terms of accuracy and computational time [78] and tools are available in freely available packages, such as SNAP, developed by the ESA to estimate LAI, fractional vegetation cover, and other parameters from Sentinel-2 data (https://sentinel.esa.int/web/sentinel/toolboxes/sentinel-2). Experimental studies have shown the accuracy of this approach for LAI or ET estimation in different environments and crops. 
The weakness of RSEB approaches is the representativeness of the ET estimates over time because they provide an instantaneous estimation of the ET at the image acquisition time. This instantaneous value must be extrapolated to daily amounts on a physical basis, such as the conservation of the energy partitioning [99] or the stability of the crop coefficient [89]. The time gaps between estimates of ET for all satellite systems may bias daily-to-seasonal estimates. As pointed out by Allen et al. [89] the effects of precipitation or irrigation events occurring between satellite overpasses may be missed, resulting in underestimation of seasonal ET with respect to the actual value. In addition, processing of images impacted from recent precipitation events could lead an overestimation of the seasonal values of ET if these images are used in the interpolation. In the framework of NIWR estimates, another operative issue is the adequate interpretation of ET data obtained under water stress conditions. According to the definitions provided in the introduction, NIWR is the amount of water that should be applied in order to maintain the crop transpiring at its potential rate. Acquiring ET data under water stress conditions could lead to an underestimation of NIWR if the actual values are not compared with the potential (and eventually desired) ET rates for the analyzed canopies. In addition to these weaknesses, the limited availability of thermal observations in terms of spatial and temporal resolution hampers the development of operational applications of surface energy balance from remote sensing.

In general terms, the main difference between RSEB models with respect to RS-PM and reflectance based $\mathrm{Kcb}$ approaches is the assessment of water stress, but the three approaches should result in similar values when applied under non-water limited conditions. In this line, Singh and Irmak [43] found that a Kc-NDVI relationship derived from the SEBAL model is able to reproduce the actual ET measured with a Bowen ratio station. Tasumi et al. [41] concluded that the ET estimates from a Kc-NDVI relationships correspond well with the results of METRIC applied for multiple crops in an irrigated area in Idaho. Rafn et al. [42] demonstrated that the results of three Kc-NDVI relationships, derived from empirical or analytical approaches, are within the range of $\pm 10 \%$ of the ET estimate based on the METRIC model. Rubio et al. [100] published a direct comparison of two RSEB models, the RS-PM approach and the reflectance-based Kcb. These authors concluded that the RS-PM and reflectance-based Kcb models are in agreement with each other, although these authors did avoid the direct comparison of both approaches with RSEB models because of their different nature. Similarly, D'Urso et al. [112] obtained a comparable accuracy when the reflectance-based Kcb and the RS-PM models are applied to herbaceous crops, like corn, alfalfa, and wheat. Gonzalez-Dugo et al. [99] compared three RSEB models and the reflectance-based Kcb approach for the assessment of ET in irrigated herbaceous crops. These authors obtained similar accuracy for every model, but the 2-sources RSEB and the reflectance-based Kcb were the approaches with lower RMSE. In the view of the results, we can conclude that all models were valid for the assessment of the ET of irrigated herbaceous crops. Although each model has been evaluated in other crops, as is the case of horticultural and fruit threes, we did not find comparative studies running different models on the same conditions. Future studies comparing different approaches for these crops and in operative schemes will provide further insights on model performance.

\subsection{Comparison of the decision support systems based on web-GIS technology}

The development of operational systems for the assessment of water management confirm the maturity and the applicability of the methodologies revised in this paper. The advantages and improvements over traditional irrigation advisory services based on field work and Kc-tabulated values, refer to the capability of the satellite-based system to reflect the actual conditions of the canopy, covering large areas and increasing efficiency of field work. Further experiences about the transferability of these methods are developed in the framework of EU-funded projects as SIRIUS (http://sirius-gmes.es) and FATIMA (http://fatima-h2020.eu). In the frame of SIRIUS, the groups involved provided information related with the CWR and NIRW in several pilot areas (from the Americas to Asia) and for a wide range of end-users and stakeholders, from farmers to water authorities. The information currently provided to the end-users in the frame of FATIMA varies from 
NIWR maps to spatially distributed fertilization requirements adapted to the actual crop development and potential productivity.

The experience obtained in these projects indicate that additional conclusions can be extracted if the methodology is analysed from the perspective of the end user (V. Bodas, personal communication). Easy access to timely information is crucial. Direct access by farmers in real-time to the images in the way of the usual RGB colour combination is very useful. These RGB/NDVI images enable farmers to gain confidence in identifying some details in the images they have observed directly in their fields, such as sprinkler failure and non-uniformity water distribution effects, among others. These conclusions are shared by the different web-GIS analyzed, and the basic information provided by each system is similar: vegetation indices, color composites, and core biophysical parameters derived from satellite data and related with the water use, like crop coefficients. All of the systems take into account the necessity of the spatio-temporal analysis, and the user can visualize the images and query the information for different dates or time periods. An interesting option in all systems is the capability to display the location of the user or device in the maps. This geolocation, with the reference of the most recent satellite images, can be used to identify areas of interest in the field, like zones with unusual crop development. An additional point of general agreement is that weekly is the best compromise of timing for using and receiving the information about plant status and CWR. However, the information about CWR or NIWR must be provided with sufficient anticipation, because of the time required to modify the irrigation scheduling, adapted to the power supply rates, water availability, irrigation system, precipitation probability and farmer's availability.

Usually the farmers are willing to adopt these techniques are familiar with point ground moisture sensors in such a way that they are able to check with their own knowledge the reliability of RS recommendations, comparing them with other sources of water requirement estimation. This necessity is considered in most of the systems although the information provided and the procedures varies between the systems. IrriSatSMS has powerful processing capabilities because it is able to calculate, on-the-fly, a soil water balance for the user-drawn polygon. The system is able to estimate and update the actual NIWR and soil water content based on the information provided by the end user. The information about NIWR and other components of the satellite-based soil water balance can be displayed in other web-GIS tools, like SPIDER or IRRISAT, but must be processed off-line. An example of the implementation of an RS-based soil water balance for the whole Iberian Peninsula at the pixel scale in irrigated areas can be seen in the SPIDER group named SPIDER-CENTER (http://maps.spiderwebgis.org/login/?custom=spider-center). This project is funded by the Spanish Ministry of Agriculture (for further information and accessibility the reader is referred to http://www.magrama.gob.es/es/desarrollo-rural/temas/centro-nacional-tecnologia-regadios/nuevasaplicaciones-tecnologicas/).

An additional difference between the various systems is the accessibility to pixel- or plot-based information. IRRISAT, EO4Water and IRRiEYE provide information at the pixel and plot scale. IrriSatSMS emphasizes on the plot scale. SPIDER and TOP-SIMS allow the direct comparison of multiple pixels or small grids. SPIDER provides a dynamic multi-chart with the temporal evolution of the selected parameters for different locations. This capability opens the possibility to show and compare the spatial distribution of the CWR or related variables and may be of interest for the analysis of crop uniformity. Although irrigation and other tasks are currently planned and performed for the whole plot, new machinery for variable rate irrigation is becoming available. The accurate generation of spatial irrigation recommendation, as is the case of NIWR maps at the pixel scale based on RS, is essential for implementation and evaluation of the technologies [136].

Table 2. Relevant aspects of the web-GIS based decision support systems analyzed in the text.

\begin{tabular}{|c|l|l|l|l|}
\hline & \multicolumn{1}{|c|}{ Irrisat } & \multicolumn{1}{c|}{ TOP-SIMS } & \multicolumn{1}{c|}{ IrriSat-SMS } & \multicolumn{1}{c|}{ SPIDER } \\
\hline Accessibility & $\begin{array}{l}\text { User and } \\
\text { password }\end{array}$ & Open & $\begin{array}{l}\text { Accessible with } \\
\text { Gmail account }\end{array}$ & $\begin{array}{l}\text { User and } \\
\text { password }\end{array}$ \\
\hline Base maps & $\begin{array}{l}\text { Google Satellite / } \\
\text { Open street maps }\end{array}$ & $\begin{array}{l}\text { Google Satellite / } \\
\text { Google Terrain }\end{array}$ & $\begin{array}{l}\text { Google Satellite / } \\
\text { Google Terrain }\end{array}$ & $\begin{array}{l}\text { Google maps / } \\
\text { Open street map }\end{array}$ \\
\hline
\end{tabular}




\begin{tabular}{|c|l|l|l|l|}
\hline $\begin{array}{c}\text { Processing } \\
\text { time }\end{array}$ & $\begin{array}{l}24 \mathrm{~h} \text { after } \\
\text { delivery }\end{array}$ & - & $\begin{array}{l}\text { Automatic after } \\
\text { delivery }\end{array}$ & $\begin{array}{l}\text { 24 h after } \\
\text { delivery }\end{array}$ \\
\hline $\begin{array}{c}\text { RS-based } \\
\text { approach }\end{array}$ & RS-PM & Kcb-VI & Kcb-VI \\
\hline $\begin{array}{c}\text { Most } \\
\text { elaborated } \\
\text { product }\end{array}$ & $\begin{array}{l}\text { Maps of irrigated } \\
\text { areas, LAI, CWR }\end{array}$ & $\begin{array}{l}\text { Maps of Kcb and } \\
\text { crop transpiration }\end{array}$ & $\begin{array}{l}\text { Water balance } \\
\text { components }\end{array}$ & $\begin{array}{l}\text { Maps of Kcb, ETo } \\
\text { and CWR }\end{array}$ \\
\hline Coverage & $\begin{array}{l}\text { Campania Region } \\
\text { (Italy); } \\
\text { Bookpournong } \\
\text { (Australia) }\end{array}$ & California & $\begin{array}{l}\text { Global, ETo } \\
\text { available for the } \\
\text { East of Australia }\end{array}$ & $\begin{array}{l}\text { Pilot areas, } \\
\text { 400.000 Km } \text { for }^{2} \text { for } \\
\text { the largest } \\
\text { project. }\end{array}$ \\
\hline $\begin{array}{c}\text { Period } \\
\text { covered }\end{array}$ & 2007-2016 & 2010-2012 & 2014-2016 & 2013-2016 \\
\hline $\begin{array}{c}\text { Dedicated } \\
\text { App }\end{array}$ & No & No & No & Yes \\
\hline
\end{tabular}

\section{Conclusions and Perspectives}

The experiences gathered during the past 30 years support the operational use of irrigation scheduling based on spectral inputs. Currently, the operational use of dense time series of multispectral imagery at high spatial resolution allows monitoring of crop biophysical parameters related with crop water use during the growing season with an unprecedent temporal and spatial resolution. This information is needed and highly appreciated by the end users, such as professional farmers or decision-makers, but several steps are necessary prior to introducing this information into the day-to-day routine of farming irrigation. The information about crop water requirements must be provided with sufficient anticipation, and one week ahead seems to be a reasonable lead time. In addition, the end users require access to this information and to the time series of images in an easyto-use way and in near real-time. This information can be provided in an easy-to-use way and in near real-time by using the improvements achieved in web-GIS methodologies and further developments, like mobile apps. The achievement in crop ET assessment, the accessibility to satellite images, and the availability of accurate forecasting of meteorological data allow for precise predictions of crop water requirements.

\section{Acknowledgements}

This research was developed in the framework of the project FATIMA (FArming Tools for external nutrient Inputs and water MAnagement), funded by the European Union's Horizon 2020 research and innovation programme (Grant Agreement № 633945).

\section{References}

1. FAO Building a common vision for sustainable food and agriculture. PRINCIPLES AND APPROACHES; 2014.

2. Tilman, D.; Cassman, K. G.; Matson, P. A.; Naylor, R.; Polasky, S. Agricultural sustainability and intensive production practices. Nature 2002, 418, 671-677.

3. Garnett, T.; Appleby, M. C.; Balmford, A.; Bateman, I. J.; Benton, T. G.; Bloomer, P.; Burlingame, B.; Dawkins, M.; Dolan, L.; Fraser, D.; Herrero, M.; Hoffmann, I.; Smith, P.; Thornton, P. K.; Toulmin, C.; Vermeulen, S. J.; Godfray, H. C. J. Sustainable Intensification in Agriculture: Premises and Policies. Sci. Mag. 2013, 341, 33-34.

4. Jensen, M. E.; Burman, R. D.; Allen, R. G. Evapotranspiration and irrigation water requirements; 1990; 
Vol. 1.

5. Doorenbos, J.; Pruitt, W. O. Guidelines for predicting crop water requierements. Irrig. Drain. Pap. No. 24, FAO, Rome, Italy 1977.

6. Allen, R. G.; Raes, D.; Smith, M. Crop evapotranspiration: Guidelines for computing crop requirements. Irrig. Drain. Pap. No. 56, FAO, Rome, Italy 1998.

7. Doorenbos, J.; Kassam, A. H. Yield response to water; Food and Agriculture Organization of the United Nations: Rome, 1979.

8. Steduto, P.; Hsiao, T. C.; Fereres, E.; Raes, D. Crop yield response to water. FAO Irrig. Drain. Pap. No.66 2012, 505.

9. Bastiaanssen, W.; Allen, R. G.; Droogers, P.; D’Urso, G.; Steduto, P. Twenty -five years modelng irrigated and drained soils: State of the art. Agric. Water Manag. 2007, 92, 111-125.

10. Pinter, P.; Ritchie, J.; Hatfield, J.; Hart, G. The Agricultural Research Service's remote sensing program: An example of interagency collaboration. Photogramm. Eng. Remote Sensing 2003, 69, 615618.

11. Jackson, R. Remote Sensing of Vegetation Characteristics for Farm Management. In Proceedings of the Society of Photo Optical Instrumentation Engineers; 1984; pp. 81-96.

12. Allen, R. G.; Pereira, L. S.; Howell, T. A.; Jensen, M. E. Evapotranspiration information reporting: I. Factors governing measurement accuracy. Agric. Water Manag. 2011, 98, 899-920.

13. D'Urso, G. Current Status and Perspectives for the Estimation of Crop Water Requirements from Earth Observation. Ital. J. Agron. 2010, 5, 107-120.

14. Shuttelworth, W. Evaporation models in hydrology. In Land Surface Evaporation Measurement and Parameterization; Schmugge, T. J.; André, J.-C., Eds.; Springer: New York, 1991; pp. 93-120.

15. Monteith, J. L.; Unsworth, M. Principles of Environmental Physics; Academic Press.: Burlington, USA, 1990.

16. Jensen, M. E.; Robb, D. C. N.; Franzoy, C. E. Scheduling irrigations using climate-crop-soil data. J. Irrig. Drain. Eng. 1970, 96, 25-38.

17. Wright, J. L. New Evapotranspiration Crop Coefficients. J. Irrig. Drain. Div. 1982, 108, 57-74.

18. Kanemasu, E. T. Seasonal canopy reflectance patterns of wheat, sorghum, and soybean. Remote Sens. Environ. 1974, 3, 43-47.

19. Tucker, C. J.; Elgin Jr., H. J.; McMurtrey, J. E. I.; Fran, C. J. Monitoring corn and soybean crop development with hand-held radiometer spectral data. Remote Sens. Environ. 1979, 8, 237-248.

20. Pinter, P.; Hatfield, J. L. L.; Schepers, J. S. S.; Barnes, E. M. M.; Moran, M. S. S.; Daughtry, C. S. T. S. T.; Upchurch, D. R. R. Remote sensing for crop management. Photogramm. Eng. Remote Sens. 2003, $69,647-664$.

21. Jackson, R. D.; Idso, S. B.; Regionato, R. J.; Pinter Jr., P. J. Remotely sensed crop temperatures and reflectances as inputs to irrigation scheduling. In Irrigation and Drainage Special Conference Proceedings, ASCE; Boise, N.Y., USA, 1980; pp. 390-397. 
22. Bausch, W. C.; Neale, C. M. U. Crop coefficients derived from reflected canopy radiation - a concept. Trans. ASAE 1987, 30, 703-709.

23. Neale, C.; Bausch, W.; Heerman, D. Development of reflectance-based crop coefficients for corn. Trans. ASAE 1989, 32, 1891-1899.

24. Heilman, J. L.; Heilman, W. E.; Moore, D. G. Evaluating the crop coefficient using spectral relfectance. Agron. J. 1982, 74, 967-971.

25. Asrar, G.; Myneni, R. B.; Choundhury, B. J. Spatial heterogeneity in vegetation canopies and remote sensing of absorbed photosynthetically active radiation: A modelling study. Remote Sens. Environ. 1992, 41, 85-103.

26. Baret, F.; Guyot, G. Potentials and limits of vegetation indices for LAI and APAR assessment. Remote Sens. Environ. 1991, 35, 161-173.

27. Pinter, P. J. Solar angle independence in the relationship between absorbed PAR and remotely sensed data for alfalfa. Remote Sens. Environ. 1993, 46, 19-25.

28. Sellers, P. J.; Berry, J. A.; Collatz, G. J.; Field, C. B.; Hall, F. G. Canopy reflectance, photosynthesis, and transpiration. III. A reanalysis using improved leaf models and a new canopy integration scheme. Remote Sens. Environ. 1992, 42, 187-216.

29. Choudhury, B. J.; Ahmed, N. U.; Idso, S. B.; Reginato, R. J.; Daughtry, C. S. Relations between evaporation coefficients and vegetation indices studied by model simulations. Remote Sens. Environ. 1994, 50, 1-17.

30. Duchemin, B.; Hadria, R.; Er-Raki, S.; Boulet, G.; Maisongrande, P.; Chehbouni, A.; Escadafal, R.; Ezzahar, J.; Hoedjes, J. C. B.; Kharrou, M. H.; Khabba, S.; Mougenot, B.; Olioso, A.; Rodriguez, J. C.; Simmoneaux, V. Monitoring wheat phenology and irrigation in central Morocco: On the use of relationships between evapotranspiration, crop coefficients, leaf area index and remotely-sensed vegetation indices. Agric. Water Manag. 2006, 79, 1-27.

31. Jayanthi, H.; Neale, C. M. U.; Wright, J. L. Development and validation of canopy reflectancebased crop coefficient for potato. Agric. Water Manag. 2007, 88, 235-246.

32. Hunsaker, D. J.; Barnes, E. M.; Clarke, T. R.; Fitzgerald, G. J.; Pinter Jr., P. R. Cotton irrigation scheduling using remotely sensed and FAO-56 basal crop coefficients. Trans. ASAE 2005, 48, 13951407.

33. González-Dugo, M. P.; Mateos, L. Spectral vegetation indices for benchmarking water productivity of irrigated cotton and sugarbeet crops. Agric. Water Manag. 2008, 95, 48-58.

34. Johnson, L. F.; Trout, T. J. Satellite NDVI assisted monitoring of vegetable crop evapotranspiration in california's san Joaquin Valley. Remote Sens. 2012, 4, 439-455.

35. Samani, Z.; Bawazir, A. S.; Bleiweiss, M.; Skaggs, R.; Longworth, J.; Tran, V. D.; Pinon, A. Using remote sensing to evaluate the spatial variability of evapotranspiration and crop coefficient in the lower Rio Grande Valley, New Mexico. Irrig. Sci. 2009, 28, 93-100.

36. Campos, I.; Neale, C. M. U.; Calera, A.; Balbontin, C.; González-Piqueras, J. Assesing satellitebased basal crop coefficients for irrigated grapes (Vitis vinifera L.). Agric. Water Manag. 2010, 98, 45- 
54.

37. Er-Raki, S.; Rodriguez, J. C.; Garatuza-Payan, J.; Watts, C. J.; Chehbouni, A. Determination of crop evapotranspiration of table grapes in a semi-arid region of Northwest Mexico using multispectral vegetation index. Agric. Water Manag. 2013, 122, 12-19.

38. Odi-Lara, M.; Campos, I.; Neale, C. M. U.; Ortega-Farias, S.; Poblete-Echeverria, C.; Balbontin, C.; Calera, A. Estimating evapotranspiration of an apple orchard using a remote sensing-based soil water balance. Remote Sens. 2016, 8 .

39. Nagler, P. L.; Morino, K.; Murray, R.; Osterberg, J.; Glenn, E. P. An empirical algorithm for estimating agricultural and riparian evapotranspiration using MODIS Enhanced Vegetation Index and ground ground measurements of ET. I. Descpription of method. Remote Sens. 2009, 1.

40. Groeneveld, D. P.; Baugh, W. M.; Sanderson, J. S.; Cooper, D. J. Annual groundwater evapotranspiration mapped from single satellite scenes. J. Hydrol. 2007, 344, 146-156.

41. Tasumi, M.; Allen, R. G.; Trezza, R. Calibrating satellite-based vegetation indices to estimate evapotranspiration and crop coefficients. In USCID Water Management Conference; Denver, Colorado. USA, 2006.

42. Rafn, E. B.; Contor, B.; Ames, D. P. Evaluation of a Method for Estimating Irrigated CropEvapotranspiration Coefficients from Remotely Sensed Data in Idaho. J. Irrig. Drain. Eng. 2008, 134, 722-729.

43. Singh, R. K.; Irmak, A. Estimation of Crop Coefficients Using Satellite Remote Sensing. J. Irrig. Drain. Eng. 2009, 135, 597-608.

44. Calera, A.; González-Piqueras, J.; Melia, J. Monitoring barley and corn growth from remote sensing data at field scale. Int. J. Remote Sens. 2004, 25, 97-109.

45. Wiegand, C. L.; Richardson, A. J. Use of spectral vegetation indices to infer leaf area, evapotranspiration and yield: I. Rationale. Agron. J. 1990, 82, 623-629.

46. Bauer, M. E. SPECTRAL INPUTS TO CROP IDENTIFICATION AND CONDITION ASSESSMENT. Proc. IEEE 1985, 73, 1071-1085.

47. Mateos, L.; González-Dugo, M. P.; Testi, L.; Villalobos, F. J. Monitoring evapotranspiration of irrigated crops using crop coefficients derived from time series of satellite images. I. Method validation. Agric. Water Manag. 2013, 125, 81-91.

48. Hunsaker, D. J.; Pinter, P. J.; Barnes, E. M.; Kimball, B. A. Estimating cotton evapotranspiration crop coefficients with a multispectral vegetation index. Irrig. Sci. 2003, 22, 95-104.

49. Torres, E. A.; Calera, A. Bare soil evaporation under high evaporation demand: a proposed modification to the FAO-56 model. Hydrol. Sci. J. 2010, 55, 303-315.

50. Martinez-Beltran, C.; Jochum, M. A. O.; Calera, A.; Melia, J. Multisensor comparison of NDVI for a semi-arid environment in Spain. Int. J. Remote Sens. 2009, 30, 1355-1384.

51. Moran, M. S.; Bryant, R.; Thome, K.; Ni, W.; Nouvellon, Y.; Gonzalez-Dugo, M. P.; Qi, J.; Clarke, T. R. A refined empirical line approach for reflectance factor retrieval from Landsat-5 TM and Landsat-7 ETM+. Remote Sens. Environ. 2001, 78, 71-82. 
52. Danaher, T. An Empirical BRDF Correction for Landsat TM and ETM + Imagery. In Proceedings of the 11th Australasian Remote Sensing and Photogrammetry Conference; 2002; p. pp. 12.

53. Fensholt, R.; Sandholt, I.; Rasmussen, M. S. Evaluation of MODIS LAI, fAPAR and the relation between FAPAR and NDVI in a semi-arid environment using in situ measurements. Remote Sens. Environ. 2004, 91, 490-507.

54. Tardieu, F.; Simonneau, T. Variability among species of stomatal control under fluctuating soil water status and evaporative demand: modelling isohydric and anisohydric behaviours. J. Exp. Bot. 1998, 49, 419-432.

55. Yamori, W.; Hikosaka, K.; Way, D. A. Temperature response of photosynthesis in C3, C4, and CAM plants: Temperature acclimation and temperature adaptation. Photosynth. Res. 2014, 119, 101117.

56. Campos, I.; Villodre, J.; Carrara, A.; Calera, A. Remote sensing-based soil water balance to estimate Mediterranean holm oak savanna (dehesa) evapotranspiration under water stress conditions. J. Hydrol. 2013, 494, 1-9.

57. Hornbuckle, J. Final report to Grape and Wine Research \& Development Corporation; 2014.

58. Trout, T. J.; Johnson, L. F. Estimating crop water use from remotely sensed NDVI, Crop Models and Reference ET. In USCID Fourth International Conference on Irrigation and Drainage, The Role of Irrigation and Drainage in a Sustainable Future; Clemmens, A. J.; Anderson, S. ., Eds.; Sacramento, California, 2007.

59. Melton, F. S.; Johnson, L. F.; Lund, C. P.; Pierce, L. L.; Michaelis, A. R.; Hiatt, S. H.; Guzman, A.; Adhikari, D. D.; Purdy, A. J.; Rosevelt, C.; Votava, P.; Trout, T. J.; Temesgen, B.; Frame, K.; Sheffner, E. J.; Nemani, R. R. Satellite irrigation management support with the terrestrial observation and prediction system: A framework for integration of satellite and surface observations to support improvements in agricultural water resource management. IEEE J. Sel. Top. Appl. Earth Obs. Remote Sens. 2012, 5, 1709-1721.

60. Hunsaker, D. J.; Pinter Jr., P. R.; Kimball, B. A. Wheat basal crop coefficients determined by normalized difference vegetation index. Irrig. Sci. 2005, 22, 95-104.

61. Bausch, W. C. Soil background effects on reflectance-based crop coefficients for corn. Remote Sens. Environ. 1993, 46, 213-222.

62. D'Urso, G.; Menenti, M.; Santini, A. Regional application of one-dimensional water flow models for irrigation management. In Agricultural Water Management; 1999; Vol. 40, pp. 291-302.

63. Consoli, S.; D'Urso, G.; Toscano, A. Remote sensing to estimate ET-fluxes and the performance of an irrigation distric in southern Italy. Agric. Water Manag. 2006, 81, 295-314.

64. Myneni, R. B. Estimation of global leaf area index and absorbed par using radiative transfer models. IEEE Trans. Geosci. Remote Sens. 1997, 35, 1380-1393.

65. Shi, H.; Xiao, Z.; Liang, S.; Zhang, X. Consistent estimation of multiple parameters from MODIS top of atmosphere reflectance data using a coupled soil-canopy-atmosphere radiative transfer model. Remote Sens. Environ. 2016, 184, 40-57. 
66. Mu, Q. Z.; Zhao, M.; Running, S. W. Improvements to a MODIS global terrestrial evapotranspiration algorithm. Remote Sens. Environ. 2011, 115, 1781-1800.

67. Mu, Q.; Heinsch, F. A.; Zhao, M.; Running, S. W. Development of a global evapotranspiration algorithm based on MODIS and global meteorology data. Remote Sens. Environ. 2007, 111, 519-536.

68. Leuning, R.; Zhang, Y. Q.; Rajaud, A.; Cleugh, H.; Tu, K. A simple surface conductance model to estimate regional evaporation using MODIS leaf area index and the Penman-Monteith equation. Water Resoures Res. 2008, 44, W10419, 17 PP.

69. Zhang, K.; Kimball, J. S.; Mu, Q. Z.; Jones, L. A.; Goetz, S. J.; Running, S. W. Saltellite based analysis of northern ET trends and associated changes in the regional water balance from 1983 to 2005. J. Hydrol. 2009, 379, 92-110.

70. Zhang, Y. Q.; Chew, F. H. S.; Zhong, L.; Li, H. X. Use of remotely sensed actual evapotranspiration to improve rainfall-runoff modeling in Southeast Australia. J. Hydrol. Meteorol. 2009, 10, 969-980.

71. Zhang, Y. Q.; Chiew, F. H. S.; Zhang, L.; Leuning, R.; Cleugh, H. A. Estimating catchment evaporation and runoff using MODIS leaf area index and the Penman-Monteith equation. Water Resoures Res. 2008, 44, W10420, 15 PP.

72. Azzali, S.; Menenti, M.; Meeuwissen, I. J. M.; Visser, T. N. M. Application of remote sensing techniques to map crop coefficients in an Argentinian irrigation scheme. In Advances in Water Research; Tsakiris, G., Ed.; Balkema, Rotterdam, 1991; pp. 637-643.

73. Vanino, S.; Pulighe, G.; Nino, P.; De Michele, C.; Bolognesi, S. F.; D’Urso, G. Estimation of Evapotranspiration and Crop Coefficients of Tendone Vineyards Using Multi-Sensor Remote Sensing Data in a Mediterranean Environment. Remote Sens. 2015, 7, 14708-14730.

74. Cammalleri, C.; Ciraolo, G.; Minacapilli, M.; Rallo, G. Evapotranspiration from an Olive Orchard using Remote Sensing-Based Dual Crop Coefficient Approach. Water Resour. Manag. 2013, 27, 48774895 .

75. Vuolo, F.; D’Urso, G.; De Michele, C.; Bianchi, B.; Cutting, M. Satellite-based irrigation advisory services: A common tool for different experiences from Europe to Australia. Agric. Water Manag. 2015, 147, 82-95.

76. Anderson, M. C.; Neale, C. M. U.; Li, F.; Norman, J. M.; Kustas, W. P.; Jayanthi, H.; Chavez, J. Upscaling ground observations of vegetation water content, canopy height, and leaf area index during SMEX02 using aircraft and Landsat imagery. Remote Sens. Environ. 2004, 92, 447-464.

77. Vuolo, F.; Neugebauer, N.; Bolognesi, S. F.; Atzberger, C.; D’Urso, G. Estimation of leaf area index using DEIMOS-1 data: Application and transferability of a semi-empirical relationship between two agricultural areas. Remote Sens. 2013, 5, 1274-1291.

78. Duveiller, G.; Weiss, M.; Baret, F.; Defourny, P. Retrieving wheat Green Area Index during the growing season from optical time series measurements based on neural network radiative transfer inversion. Remote Sens. Environ. 2011, 115, 887-896.

79. Bastiaanssen, W. G. M.; Menenti, M.; Feddes, R. A.; Holstlag, A. A. M. A remote sensing surface energy balance algorithm for land (SEBAL). 1. Formulation. J. Hydrometeorol. 1998, 212-213, 198-212. 
80. Gillies, R. T.; Carlson, T. N.; Cui, J.; Kustas, W. P.; Humes, K. S. A verification of the "triangle" method for obtaining surface soil water content and energy fluxes from remote measurements of the Normalized Difference Vegetation Index (NDVI) and surface radiant temperatures. Int. J. Remote Sens. 1997, 18, 3145-3166.

81. Kustas, W. P.; Norman, J. M. Use of remote sensing for evapotranspiration monitoring over land surfaces. Hydrol. Sci. 1996, 41, 495-516.

82. Moran, M. S.; Clarke, T. R.; Inoue, Y.; Vidal, A. Estimating crop water deficit using the relation between surface-air temperature and spectral vegetation index. Remote Sens. Environ. 1994, 49, $246-$ 263.

83. Menenti, M. Understanding land surface evapotranspiration with satellite multispectral measurements. Adv. Sp. Res. 1993, 13, 89-100.

84. Norman, J. M.; Kustas, W. P.; Humes, K. S. A two-source approach for estimating soil and vegetation energy fluxes in observations of directional radiometric surface temperature. Agric. For. Meteorol. 1995, 77, 263-293.

85. Chehbouni, A.; Seen, D. L.; Njoku, E. G.; Monteney, B. M. Examination of difference between radiometric and aerodynamic surface temperature over sparsely vegetated surfaces. Remote Sens. Environ. 1996, 58, 177-186.

86. Kustas, W. P.; Choudhury, B. J.; Moran, M. S.; Reginato, R. D.; Jackson, R. D.; Gay, L. W.; Weaver, H. L. Determination of sensible heat flux over sparse canopy using thermal infrared data. Agric. For. Meteorol. 1989, 44, 197-216.

87. Lhomme, J. P.; Monteny, B.; Amadou, M. Estimating sensible heat flux from radiometric temperature over sparse millet. Agric. For. Meteorol. 1994, 68, 77-91.

88. Mahrt, L.; Vickers, D. Bulk formulation of the surface heat flux. Bound. Layer Meteorol. 2004, 110, 357-379.

89. Allen, R. G.; Tasumi, M.; Trezza, R. Satellite-based energy balance for mapping evapotranspiration with internalized calibration (METRIC)-Model. J. Irrig. Drain. Eng. 2007, 133, 380-394.

90. Menenti, M.; Bastiaanssen, W.; van Eick, D.; Abd el Karim, M. A. Linear relationships between surface reflectance and temperature and their application to map actual evaporation of groundwater. Adv. Sp. Res. 1989, 9, 165-176.

91. Su, Z. The Surface Energy Balance System (SEBS) for estimation of turbulent heat fluxes. Hydrol. Earth Syst. Sci. 2002, 6, 85-99.

92. Shuttelworth, W.; Wallace, J. Evaporation from sparse crops: An energy combination theory. Q. J. R. Meteorol. Soc. 1985, 111, 1143-1162.

93. Anderson, M. C.; Norman, J. M.; Mecikalski, J. R.; Otkin, J. A.; Kustas, W. P. A climatological study of evapotranspiration and moisture stress across the continental United States based on thermal remote sensing: 1. Model formulation. J. Geophys. Res. 2007, 112, D10117.

94. Anderson, M. C.; Kustas, W. P.; Norman, J. M.; Hain, C. R.; Mecikalski, J. R.; Schultz, L.; 
González-Dugo, M. P.; Cammalleri, C.; D’Urso, G.; Pimstein, A.; Gao, F. Mapping daily evapotranspiration at field to continental scales using geostationary and polar orbiting satellite imagery. Hydrol. Earth Syst. Sci. 2010, 15, 223-239.

95. Menenti, M.; Choudhury, B. J. Parameterization of land surface evaporation by means of location dependent potential evaporation and surface temperature range. Proc. IAHS Conf. L. Surf. Process. 1993, 0, 561-568.

96. Idso, S. B.; Jackson, R. D.; Pinter Jr., P. J.; Reginato, R. J.; Hatfield, J. L. Normalizing the stressdegree-day parameter for environmental variability. Agric. Meteorol. 1981, 24, 45-55.

97. Chirouze, J.; Boulet, G.; Jarlan, L.; Fieuzal, R.; Rodriguez, J. C.; Ezzahar, J.; Er-Raki, S.; Bigeard, G.; Merlin, O.; Garatuza-Payan, J.; Watts, C.; Chehbouni, G. Intercomparison of four remotesensing-based energy balance methods to retrieve surface evapotranspiration and water stress of irrigated fields in semi-arid climate. Hydrol. Earth Syst. Sci. 2014, 18, 1165-1188.

98. Palladino, M.; Staiano, A.; D’Urso, G.; Minacapilli, M.; Rallo, G. Mass and Surface Energy Balance Approaches for Monitoring Water Stress in Vineyards. Procedia Environ. Sci. 2013, 19, 231238.

99. Gonzalez-Dugo, M. P.; Neale, C. M. U.; Mateos, L.; Kustas, W. P.; Prueger, J. H.; Anderson, M. C.; Li, F. A comparison of operational remote sensing-based models for estimating crop evapotranspiration. Agric. For. Meteorol. 2009, 149, 1843-1853.

100. Rubio, E.; Colin, J.; D’Urso, G.; Trezza, R.; Allen, R.; Calera, A.; González, J.; Jochum, A.; Menenti, M.; Tasumi, M.; Kelly, C.; Vuolo, F. Golden day comparison of methods to retrieve et (KcNDVI, Kc-analytical, MSSEBS, METRIC). In AIP Conference Proceedings; 2006; Vol. 852, pp. 193-200.

101. Moran, M. S.; Inoue, Y.; Barnes, E. M. Opportunities and limitations for image-based remote sensing in precision crop management. Remote Sens. Environ. 1997, 61, 319-346.

102. Sandholt, I.; Rasmussen, K.; Andersen, J. A simple interpretation of the surface temperature/vegetation index space for assessment of surface moisture status. Remote Sens. Environ. 2002, 79, 213-224.

103. Alderfasi, A. A.; Nielsen, D. C. Use of crop water stress index for monitoring water status and scheduling irrigation in wheat. Agric. Water Manag. 2001, 47, 69-75.

104. Gontia, N. K.; Tiwari, K. N. Development of crop water stress index of wheat crop for scheduling irrigation using infrared thermometry. Agric. Water Manag. 2008, 95, 1144-1152.

105. Jones, H. G. Use of infrared thermometry for estimation of stomatal conductance as a possible aid to irrigation scheduling. Agric. For. Meteorol. 1999, 95, 139-149.

106. O\&apos;Shaughnessy, S. A.; Evett, S. R.; Colaizzi, P. D.; Howell, T. A. Using radiation thermography and thermometry to evaluate crop water stress in soybean and cotton. Agric. Water Manag. 2011, 98, 1523-1535.

107. Dobrowski, S. Z.; Pusknik, J. C.; Zarco-Tejada, P. J.; Ustin, S. L. Simple reflectance indices track heat and water stress induced changes in steady state chlorophyll fluorescence. Remote Sens.

Environ. 2005, 97. 
108. Zarco-Tejada, P. J.; González-Dugo, V.; Berni, J. A. J. Fluorescence, temperature and narrowband indices acquired from a UAV platform for water stress detection using a micro-hyperspectral imager and a thermal camera. Remote Sens. Environ. 2012, 117, 322-337.

109. Zarco-Tejada, P. J.; Berjón, A.; López-Lozano, R.; Miller, J. R.; Martín, P.; Cachorro, V.; González, M. R.; de Frutos, A. Assessing vineyard condition with hyperspectral indices: Leaf and canopy reflectance simulation in a row-structured discontinuous canopy. Remote Sens. Environ. 2005, 99, 271-287.

110. Sepulcre-Canto, G.; Zarco-Tejada, P. J.; Jiménez-Muñoz, J. C.; Sobrino, J. A.; Miguel, E. de; Villalobos, F. J. Detection of water stress in an olive orchard with thermal remote sensing imagery. Agric. For. Meteorol. 2006, 136, 31-44.

111. Gao, B. C. NDWI - A normalized difference water index for remote sensing of vegetation liquid water from space. Remote Sens. Environ. 1996, 58, 257-266.

112. D’Urso, G.; Richter, K.; Calera, A.; Osann, M. A.; Escadafal, R.; Garatuza-Pajan, J.; Hanich, L.; Perdigão, A.; Tapia, J. B.; Vuolo, F. Earth Observation products for operational irrigation management in the context of the PLEIADeS project. Agric. Water Manag. 2010, 98, 271-282.

113. Neale, C.; Geli, H.; Kustas, W.; Alfieri, J.; Gowda, P.; Evett, S.; Prueger, J.; Hipps, L.; Dulaney, W. P.; Chávez, J. L.; French, A. N.; Howell, T. A. Soil water content estimation using a remote sensing based hybrid evapotranspiration modeling approach. Adv. Water Resour. 2012, 50, 152-161.

114. Chen, F.; Mitchell, K.; Schaake, J.; Xue, Y. K.; Pan, H. L.; Koren, V.; Duan, Q. Y.; Ek, M.; Betts, A. Modeling of land surface evaporation by four schemes and comparison with FIFE observations. J. Geophys. Res. 1996, 101, 7251-7268.

115. Wang-Erlandsson, L.; Bastiaanssen, W. G. M.; Gao, H.; Jägermeyr, J.; Senay, G. B.; van Dijk, A. I. J. M.; Guerschman, J. P.; Keys, P. W.; Gordon, L. J.; Savenije, H. H. G. Global root zone storage capacity from satellite-based evaporation. Hydrol. Earth Syst. Sci. Discuss. 2016, 1-49.

116. Schuurmans, J. M.; Troch, P. A.; Veldhuizen, A. A.; Bastiaanssen, W. G. M.; Bierkens, M. F. P. Assimilation of remotely sensed latent heat flux in a distributed hydrological model. Adv. Water Resour. 2003, 26, 151-159.

117. Sánchez, N.; Martínez-Fernández, J.; González-Piqueras, J.; González-Dugo, M. P.; BaronciniTurrichia, G.; Torres, E.; Calera, A.; Pérez-Gutiérrez, C. Water balance at plot scale for soil moisture estimation using vegetation parameters. Agric. For. Meteorol. 2012, 166-167, 1-9.

118. Sánchez, N.; Martínez-Fernández, J.; Calera, A.; Torres, E.; Pérez-Gutiérrez, C. Combining remote sensing and in situ soil moisture data for the application and validation of a distributed water balance model (HIDROMORE). Agric. Water Manag. 2010, 98, 69-78.

119. Sánchez, N.; Martínez-Fernández, J.; Rodríguez-Ruiz, M.; Torres, E.; Calera, A. A simulation of soil water content based on remote sensing in a semi-arid Mediterranean agricultural landscape. Spanish J. Agric. Res. 2012, 10, 521-531.

120. Colaizzi, P. D.; Barnes, E. M.; Clarke, T. R.; Choi, C. Y.; Waller, P. M. Estimating soil moinsture under low frequency surface irrigation using crop water stress index. J. Irrig. Drain. Eng. 2003, 129, 27-35. 
121. Colaizzi, P. D.; Barnes, E. M.; Clarke, T. R.; Choi, C. Y.; Waller, P. M.; Haberland, J.;

Kostrzewski, M. Water stress detection under high frequency sprinkler irrigation with water deficit index. Irrig. Drain. Eng. 2003, 129, 36-43.

122. Crow, W. T.; Kustas, W. P.; Prueger, J. H. Monitoring root-zone soil moisture through the assimilation of a thermal remote sensing-based soil moisture proxy into a water balance model. Remote Sens. Environ. 2008, 112, 1268-1281.

123. Hain, C. R.; Mecikalski, J. R.; Anderson, M. C. Retrieval of an available water-based soil moisture proxy from thermal infrared remote sensing. Part I: Methodology and validation. J. Hydrometeorol. 2009, 10, 665-683.

124. Campos, I.; Balbontin, C.; González-Piqueras, J.; González-Dugo, M. P.; Neale, C.; Calera, A. Combining water balance model with evapotranspiration measurements to estimate total available water soil water in irrigated and rain-fed vineyards. Agric. Water Manag. 2016, 165, 141-152.

125. Campos, I.; Gonzalez-Piqueras, J.; Carra, A.; Villodre, J.; Calera, A. Calibration of the soil water balance model in terms of total available water in the root zone for a continuous estimation of surface evapotranspiration in mediterranean dehesa. J. Hydrol. 2016, 534, 427-439.

126. D'Urso, G. Simulation and management of on-demand irrigation systems: a combined agrohydrological and remote sensing approach, Wageningen University, 2001.

127. Wulder, M. A.; White, J. C.; Loveland, T. R.; Woodcock, C. E.; Belward, A. S.; Cohen, W. B.; Fosnight, E. A.; Shaw, J.; Masek, J. G.; Roy, D. P. The global Landsat archive: Status, consolidation, and direction. Remote Sens. Environ. 2015.

128. Semmens, K. A.; Anderson, M. C.; Kustas, W. P.; Gao, F.; Alfieri, J. G.; McKee, L.; Prueger, J. H.; Hain, C. R.; Cammalleri, C.; Yang, Y.; Xia, T.; Sanchez, L.; Mar Alsina, M.; Vélez, M. Monitoring daily evapotranspiration over two California vineyards using Landsat 8 in a multi-sensor data fusion approach. Remote Sens. Environ. 2015.

129. Berni, J.; Zarco-Tejada, P. J.; Suarez, L.; Fereres, E. Thermal and Narrowband Multispectral Remote Sensing for Vegetation Monitoring From an Unmanned Aerial Vehicle. IEEE Trans. Geosci. Remote Sens. 2009, 47, 722-738.

130. Castaño, S.; Sanz, D.; Gómez-Alday, J. Remote Sensing and GIS Tools for the Groundwater Withdrawals Quantification. J. Agric. Sci. Appl. 2012, 1, 33-36.

131. Pôças, I.; Paço, T. A.; Paredes, P.; Cunha, M.; Pereira, L. S. Estimation of actual crop coefficients using remotely sensed vegetation indices and soil water balance modelled data. Remote Sens. 2015, 7, 2373-2400.

132. Merlin, O.; Rüdiger, C.; Al Bitar, A.; Richaume, P.; Walker, J. P.; Kerr, Y. H. Disaggregation of SMOS soil moisture in Southeastern Australia. IEEE Trans. Geosci. Remote Sens. 2012, 50, 1556-1571.

133. Sánchez, N.; Martínez-Fernánadez, J.; Scaini, A.; Pérez-Gutierrez, C. Validation of the SMOS L2 soil moisture data in the REMEDHUS network (Spain). IEEE Trans. Geosci. Remote Sens. 2012, 50, $1602-1611$.

134. Hornbuckle, J.; Car, N.; Christen, E.; Stein, T.-M.; Williamson, B. CRC for Irrigation Futures Technical Report No. 01/09 and CSIRO Land and Water Science Report No. 04/09; 2009. 
135. Nemani, R.; Hashimoto, H.; Votava, P.; Melton, F.; Wang, W.; Michaelis, A.; Mutch, L.; Milesi, C.; Hiatt, S.; White, M. Monitoring and forecasting ecosystem dynamics using the Terrestrial Observation and Prediction System (TOPS). Remote Sens. Environ. 2009, 113, 1497-1509.

136. Barker, J. B.; Neale, C. M. U.; Heeren, D. M. Evaluation of a hybrid remote sensing evapotranspiration model for variable rate irrigation management. In Emerging Technologies for Sustainable Irrigation. A joint ASABE/IA Irrigation Symposium; 2015.

137. D’Urso, G.; Richter, K.; Calera, A.; Osann, M. A.; Escadafal, R.; Garatuza-Pajan, J.; Hanich, L.; Perdigão, A.; Tapia, J. B.; Vuolo, F. Earth Observation products for operational irrigation management in the context of the PLEIADeS project. Agric. Water Manag. 2010, 98, 271-282.

138. Pelosi, A.; Medina, H.; Villani, P.; D’Urso, G.; Chirico, G. Probabilistic forecasting of reference evapotranspiration with a limited area ensemble prediction system. Agric. Water Manag. 2016, 178, $106-118$.

(C) 2016 by the authors; licensee Preprints, Basel, Switzerland. This article is an open access article distributed under the terms and conditions of the Creative Commons by Attribution (CC-BY) license (http://creativecommons.org/licenses/by/4.0/). 